\title{
A COMPARATIVE EVALUATION OF THE ACCURACY OF THIRD GENERATION ELECTRONIC APEX LOCATOR (ROOT-ZX) AND CONVENTIONAL RADIOGRAPHY - AN IN VIVO STUDY
}

\author{
Naorem Satish Kumar Singh ${ }^{1}$, N. Sukumar Singh ${ }^{2}$, Asiff Ahmed ${ }^{3}$, Pinky Thangjam ${ }^{4}$ \\ ${ }^{1}$ Assistant Professor, Department of Dentistry, J. N. Institute of Medical Sciences, Imphal. \\ ${ }^{2}$ Associate Professor, Department of Dentistry, J. N. Institute of Medical Sciences, Imphal. \\ ${ }^{3}$ Consultant Dental Surgeon, Gauhati Refinery Hospital. \\ ${ }^{4}$ Dental Surgeon, Department of Dentistry, J. N. Institute of Medical Sciences, Imphal.
}

ABSTRACT

\section{BACKGROUND}

Endodontic success lies in proper instrumentation and removal of all pulp tissue, necrotic material and microorganisms from the root canal. Traditionally, the point of termination for endodontic instrumentation and obturation has been determined by taking radiographs. But just how accurate is this radiographic measurement? The purpose of this study was to compare the accuracy of third generation electronic apex locator and radiographic technique.

\section{MATERIALS AND METHODS}

In this study, 105 anterior teeth samples are selected and divided into 6 groups of anterior teeth. Endodontic access was prepared, pulp extirpated, canals irrigated and the pulp space dried. Occlusal reference point was established. Root ZX was used according to the manufacturer's instructions to measure the working length. The working length was also measured by conventional radiography using Ingle's method.

\section{RESULTS}

The results demonstrate a statistically significant difference in the efficacy of the two. The Root ZX was able to locate the foramen with a clinical accuracy rate of $94.28 \%$ and the radiographs provided a clinical accuracy rate of $76 \%$.

\section{CONCLUSION}

Root ZX was a better choice for accurately determining the root canal length within $\pm 0.5 \mathrm{~mm}$ from the apical constriction than radiographic technique.

\section{KEYWORDS}

Electronic Apex Locator, Root ZX, Conventional Radiography, Ingle's Technique, Actual Working Length, Apical Constriction.

HOW TO CITE THIS ARTICLE: Singh NSK, Singh NS, Ahmed A, et al. A comparative evaluation of the accuracy of third generation electronic apex locator (Root-ZX) and conventional radiography - an in vivo study. J. Evolution Med. Dent. Sci. 2016;5(86):64166419, DOI: $10.14260 /$ jemds/2016/1451

\section{BACKGROUND}

Dentistry as a science which is well established today. Its beginning however perceived as an art or manual skills and are forced to re-evaluate our tools and techniques. Successful endodontic therapy depends on cutting a correct access, thorough biomechanical cleansing and a perfect three dimensional obturation. ${ }^{1,2}$ The establishment of a correct working length is one of the fundamental parameter for endodontic success. Instrumentation that is too short of or goes beyond the apical foramen will adversely affect its success. Furthermore, researchers accept Dentinocemental Junction (DCJ) as the terminal point of root canal and has been advocated as a natural point against which to pack obturation material. $^{3}$

Electronic apex locator is an adjunct to endodontic therapy and is used where radiographs are difficult to read

Financial or Other, Competing Interest: None.

Submission 07-10-2016, Peer Review 20-10-2016,

Acceptance 22-10-2016, Published 27-10-2016.

Corresponding Author:

Dr. Naorem Satish Kumar Singh,

79/10, Nagamapal Singjubung Leirak,

West Imphal-795001

Manipur.

E-mail: drnsatish@gmail.com

DOI: $10.14260 /$ jemds/2016/1451

\section{(c) $(1)(5)$}

exact working length.4,5 The principle concept of an electronic apex locator started in 1942 by Suzuki, ${ }^{6}$ whereby the electrical resistance between the periodontal membrane and the oral mucosa is a constant value of approximately 6.5 kilo ohms. In 1969, Inoue demonstrated the first generation apex locator and subsequently second, third generation apex locator were developed.7,8

Present day Apex locators are incorporated with computer programmed integrated chips, which can easily calibrate the length of the root canal. Root ZX, the latest of its kind have fewer limitations and greater ease of use, so this third generation Apex locator was selected for this study. ${ }^{9}$ The purpose of this study is to compare the accuracy and the ability of Root ZX with Ingle's radiographic method of length determination.

\section{MATERIALS AND METHODS}

For the study 105 single rooted tooth samples were taken for the study, which were intended for extraction.

Pre-operative radiographs were taken using parallel technique to determine whether or not the sampled tooth conformed to the selection criteria adopted for the study. Informed consents were obtained from all patients participating for the study. The pre-operative radiographs were utilised in order to get prior knowledge of the probable lengths of the root canals, so as to obtain greater accuracy 
while measuring them by the Root ZX and the Ingle's radiographic method.

\section{Methods for Canal Length Measurement}

A) Root ZX Apex Locator ${ }^{8,9}$ - The operating field was prepared and local anaesthesia was administered and rubber dam applied. The selected samples were accessed with a high speed hand piece. The content of the canal was not removed, but if there is abundance of pulp tissue a fine broach was used to extirpate the pulp. The lip clip of the Root ZX was hooked in the corner of the patient's mouth. The apical foramen was located with the Root ZX by advancing a compatible endodontic file towards the apex. When the apex was reached, the locator produced a particular audible sound and the APEX visual indicator on the machine's panel flashed. After flashing at apex visual indicator, the file is withdrawn to $0.5 \mathrm{~mm}$ mark.

B) Ingle's Radiographic Methods ${ }^{10}$ - Using pre-operative radiograph a rough estimation of the canal length was made and a compatible file gradually inserted into the canal upto the radiographic apex and a radiograph was taken. The distance from the tip of the file to the end of the root was measured.

C) Extraction - The sample teeth extracted were soaked in $5.25 \%$ sodium hypochlorite for 24 hours. They were then subjected to decalcification in 5\% nitric acid for 3 days with daily changing of the solution. After rinsing under tap water, the teeth were dehydrated by immersing them in $80 \%$ ethyl alcohol for 24 hours followed by $90 \%$ and $100 \%$ alcohol immersion for 1-hour period. Final immersion in methyl salicylate for 4 hours rendered the tooth transparent. The file was inserted into the canal under hand lens magnification and the length was recorded.

In all the cases, length was measured in millimetres by using the same endodontic ruler (Maillefer). Means, Standard Deviation and Standard Error of Means were calculated for each group.

\section{RESULTS}

The results demonstrate a statistical significant difference in the efficacy of the two in-situ methods of root canal measurements analysing the 105 samples; 80 were same as that of the actual root canal measurements obtained through extraction. The S.E. (Root ZX-Ext) translates an accuracy upto $76.19 \%$ when a potential error of $\pm 0.5 \mathrm{~mm}$ from the foramen is accepted as a tolerable range $(18 \%)$ for clinical application. The Root ZX was able to locate the foramen with a clinical accuracy rate of $94.28 \%$. Similarly, we can analyse the accuracy rate of the radiographs. It is seen that out of 105 radiographic readings, 62 readings were accurate, given an accuracy rate of $60.0 \%$. If an error of $\pm 0.5 \mathrm{~mm}$ from the foramen is accepted as a tolerable range for clinical application. The radiographs provided a clinical accuracy rate of $76 \%$.

\begin{tabular}{|c|c|c|c|c|}
\hline Method & $\mathbf{0}$ & $+\mathbf{- 0 . 5}$ & $+/-1$ & $>+/-1$ \\
\hline Root ZX & $80(76 \%)$ & $19(18 \%)$ & $6(5 \%)$ & $1(0.9 \%)$ \\
\hline Radiographic & $61(58 \%)$ & $18(17 \%)$ & $19(18 \%)$ & $5(4 \%)$ \\
\hline Table 1. Frequency Table showing the Number and \\
Percentage Measure with Different Method \\
\hline
\end{tabular}

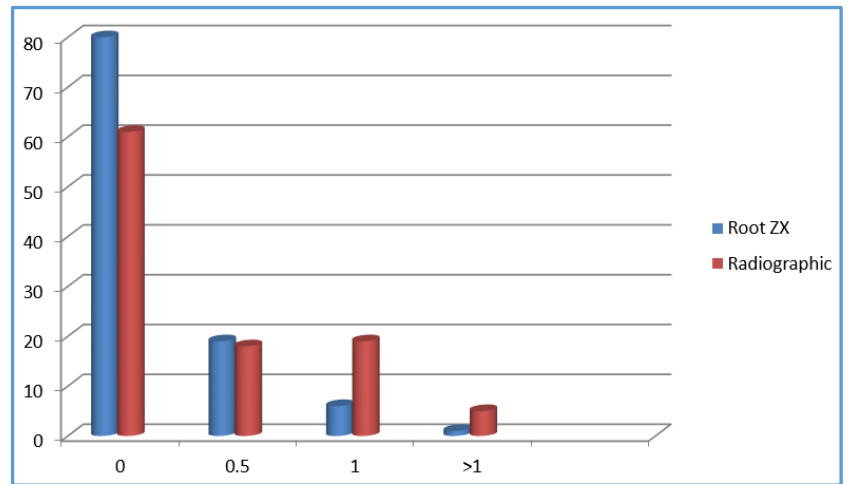

Figure 1. Frequency showing the Number and Percentage Measure with Different Method

\section{DISCUSSION}

Application of electronics in dentistry in general and on Endodontics in particular represents the role played by technology in the future. The third generation frequency based apex locators like the Root ZX uses two frequency alternating currents have emerged as efficient electronic device to determine the length of root canal.11

This study is attributed to two basic aims. First, to evaluate the accuracy of the Root ZX. Secondly, to compare the ability of the Root ZX and Ingle's radiographic method of root canal length determination with that of the actual measurements obtained after the extraction of tooth.

In this study, apical foramen was taken as the terminating point to measure the true canal length and a potential error of $\pm 0.5 \mathrm{~mm}$ from this point was accepted as tolerable range.

In our study 105 samples were first measured electronically by Root ZX, then radiographically by Ingle's method. ${ }^{10}$ After that tooth was extracted, cleared and made transparent, the actual canal length recorded. It was found that the Root ZX accurately located the apical foramen in 80 samples when compared to the length obtained after extraction of tooth with an accuracy rate of about $76 \%$. A potential error of $\pm 0.5 \mathrm{~mm}$ from the foramen was clinically accepted. The Root ZX was able to locate the foramen within a range of $76.1 \%$ in 99 samples for a clinical accuracy rate of about $94.2 \%$, which is in concurrent with the evaluation of Root ZX done by Shabahang et al $^{12}$ with a clinical accuracy of $96.2 \%$ when an error of $\pm 0.5 \mathrm{~mm}$ from the apical foramen.

Vajrabheye et al ${ }^{13}$ showed that accuracy of Root ZX with an accuracy rate of $100 \%$ when an error of $\pm 0.5 \mathrm{~mm}$ clinically. Falcheta and Castellucci 14 assessed the accuracy of Root ZX with a precise measurement in $91 \%$ cases $(n=100)$. Euiseong Kim et al ${ }^{15}$ also showed that Root-ZX alone detected the apical constriction within $\pm 0.5 \mathrm{~mm}$ in $84 \%$ of the samples (21 of 25 canals). However, $96 \%$ (24 of 25 canals) were within this range when the combination of Root $\mathrm{ZX}$ and radiographs was used. They noted no statistical significance between these 2 methods $(\mathrm{P}>$.05).

Literature also shows that radiographic method as more accurate method of measurement of canals of $88.5 \%$, then electronic devices of $73.1 \%$. It suggested the use of apex locator when an additional information was required or when radiographs alone was not efficient. ${ }^{16,17}$

Study conducted by Green $\mathrm{D}^{18}$ found that apical opening did not coincide with anatomical apex and ranges a deviation upto $2 \mathrm{~mm}$ with a mean of $0.44 \mathrm{~mm}$ in posteriors to mean deviation of $0.3 \mathrm{~mm}$ in anteriors. 
$41 \%$ of the files in our present study were found overextended beyond the foramen in radiographic method, which is in consistent with Chunn et al ${ }^{19}$ with more than $43 \%$ of the files overextended beyond the foramen.

When the Root ZX was compared with the radiographic method of length determination, it was found that out of 105 samples radiographs could locate the apical foramen in 61 samples and that of the actual length obtained after extraction with an accuracy rate of $59 \%$. But when an error of $\pm 0.5 \mathrm{~mm}$ from the apical foramen was clinically acceptable, the clinical accuracy rate was $76 \%$. The result is in consistent with the study done by Neen $\mathrm{IE}^{20}$ that apex locator when compared with radiographs showed much higher percentage of accuracy 94\% Root ZX and 73\% for radiographs. It might be attributed to the fact that the electronic apex locator used at present are much improved.

The present study showed that the Root ZX located the apical foramen in a high majority of instances. However, the radiograph of an eccentric foramen and canal of hidden curvature may show file is short of the apex. This conflicting radiographic data forced the clinician to choose between the electronic signals or radiographic images, risking over preparation of the canal.

Root ZX apex locator was more convenient to locate apical foramen than the radiographic method and can reduce the number of radiographs taken. However, radiographs are still necessary to provide information regarding canal anatomy and root morphology. When radiographic apex was considered as terminating point, then only 59\% teeth terminate at the apical foramen and were similar to result obtained by Mary J. Palmer. 4

N. J. McDonald 12 observed the ability of radiograph to provide valuable information on root canal anatomy, proximity of vital structures, size of the root canal, number of roots.

The highest number of successful measurement by Radiographic Method was found by Manuel S. Thomas et al, ${ }^{21}$ Mohamad Hosein et al, ${ }^{22}$ Bramante and Bersert, ${ }^{23}$ suggested radiographs cannot be totally eliminated which is in conformation with N. J. McDonald. ${ }^{12}$

\section{CONCLUSION}

Within the limitations of this study, the following conclusions were drawn:

1. Root ZX was a better choice by achieving an exact accuracy rate of $76.1 \%$ and if an error of $\pm 0.5 \mathrm{~mm}$ was considered clinically accuracy rate would be $94.2 \%$.

2. In Ingle's Radiography method of root canal measurement, the exact accuracy rate of about $59 \%$ was recorded, but if an error of $\pm 0.5 \mathrm{~mm}$ from the apical foramen was clinically acceptable then clinical accuracy would be $76 \%$ rate.

3. Statistical analysis of the data obtained revealed that the S. E. (Root ZX - Extraction) value was much lesser in all aspects proving that the Root ZX apex locator was more accurate than radiographs.

\section{REFERENCES}

1. ElAyouti A, Dima E, Ohmer J, et al. Consistency of apex locator function: a clinical study. J Endod 2009;35(2):17981.
2. Naito T. Better success rate for root canal therapy when treatment includes obturation short of the apex. Evid Based Dent 2005;6(2):45.

3. Wu MK, Wesselink PR, Walton RE. Apical terminus location of root canal treatment procedures. Oral Surg Oral Med Oral Pathol Oral Radiol Endod 2000;89(1):99-103.

4. Palmer MJ. Position of the apical foramen in relation to endodontic apex locator. J Endod 1991;17(6).

5. Plotino G, Grande NM, Brigante L, et al. Ex vivo accuracy of three electronic apex locators: Root ZX, elements diagnostic unit and ppex locator and ProPex. Int Endod J 2006;39(5):408-14.

6. Suzuki K. Experimental study on iontophoresis. Japanese J Stomatol 1942;16:411-29.

7. Elements Apex Locator, Instruction Guidelines, SybronEndo, Sybron Dental Specialties, Glendora, CA, 2006.

8. Gordon MPJ, Chandler NP. Electronic apex locators. Int Endod J 2004;37(7):425-37.

9. Nekoofar MH, Ghandi MM, Hayes SJ, et al. The fundamental operating principles of electronic root canal length measurement devices. Int Endod J 2006;39(8):597-609.

10. Ingle JI, Bakland IK. Endodontics. $5^{\text {th }}$ Edn. Hamilton London BC Decker 2008;pp 174.

11. Walton RE, Torabinejad M. Principles and practice of endodontic. $4^{\text {th }}$ edn. Sounders Company 2009;11:252.

12. McDonald NJ, Hovland EJ. An evaluation of the apex locator endocater. J Endod 1990;16(1):5-8.

13. Vajrabheye L, Tepmongkol P. Accuracy of apex locator. Endod Dent Traumatol 1997;13(4):180-2.

14. Falchetta M, Castellucci A. In vitro evaluation and clinical impressions of the electronic apex locator Root ZX. G Ital Endod 1993;4:173.

15. Kim E, Marmo M, Lee CY, et al. An in vivo comparison of working length determination by only root-ZX apex locator versus combining root-ZX apex locator with radiographs using a new impression technique. Oral Surg Oral Med Oral Pathol Oral Radiol Endod 2008;105(4):e79-83.

16. Hassanien EE, Hashem A, Chalfin H. Histomorphometric study of the root apex of mandibular premolar teeth: an attempt to correlate working length measured with electronic and radiograph methods to various anatomic positions in the apical portion of the canal. J Endod 2008;34(4):408-12.

17. Herrera M, Abalos C, Planas AJ, et al. Influence of apical constriction diameter on Root ZX apex locator precision. J Endod 2007;33(8):995-8.

18. Green D. A stereomicroscopic study of the root apices of 400 maxillary and mandibular anterior teeth. Oral Surg Oral Med Oral Pathol 1956;9(11):1224-32.

19. Chunn CB, Zardiackas LD, Menke RA. In-vivo root canal length determination using the forameter. J of Endod 1981;7(11):505-20.

20. Neen IE, Ananthraj A, Praveen P, et al. Comparison of digital radiography and apex locator with the conventional method in root length determination of primary teeth. Journal of Indian Society of Pedodontics and Preventive Dentistry 2011;29(4):300-4. 
21. Thomas MS, Acharya S, Kundabala M. A comparative evaluation of the accuracy of third generation electronic apex locator (root ZX) and conventional radiography to determine working length-an in-vivo study. Endodontology 2008;20(1):14-21.

22. Yosefi MH, Tabrizizadeh M, Nazari R. Evaluation of accuracy of PA radiography and Root-ZX apex locator in determination of length of teeth canal with destroyed apical constriction: an in-vitro study. Asian J Med Pharm Res 2014;4(3):136-8.
23. Bramante CM, Bersert. A clinical evaluation of some bererta methods of determining root canal length. Oral Surg Oral Med Oral Path 1974;37:463. 